\title{
Virtual Community in Interactive Teaching: Five Cases
}

\author{
${ }^{1}$ Subhenur Latif, ${ }^{2}$ Narayan Ranjan Chakraborty \\ ${ }^{1,2}$ Department of Computer Science and Engineering, Daffodil International University, Bangladesh
}

\begin{abstract}
Modern teaching methods demand innovative and effective use of technology at utmost level. Incorporating a virtual community outside classroom teaching has become inevitable in digital age education. This research was intended to find out how this can be used in terms of interactive teaching and how it can facilitate students to recover the lacks of learning in classroom. A web community of a university called Learning Feedback System (LFS) has been used here as the methodology to analyze five sample cases. Effects of a significant level of interaction in LFS indicated that it helped to reduce the communication gap between students and teachers that of course leading to proper learning.
\end{abstract}

Keywords: ICT, Interactive teaching, LFS, Technology education, Virtual Community,

\section{Introduction}

The increasing global practice of using technology as a learning tool and sophisticated technological development in the education world has been started to take effect in the education sectors of developing countries like Bangladesh [1]. The country has declared ICT as the priority sector of the economy as it is the backbone of the vision of "Digital Bangladesh". The government of Bangladesh is supporting the incorporation of technology into various levels of education including the universities.

Now technology is advancing at such a rate that traditional lectures are not fulfilling the learning potential of typical students [2]. The proper use of interactive communication technologies (blog, online discussion, video and audio conference etc.) can advance the traditional ways of teaching and learning extensively and can reduce a number of problems associated with manual process. With the help of these technologies, educational institutions are now promoting different methods of learning for getting better academic performance of students. It is often hard for one to explain a critical learning topic clearly to everyone through traditional class discussions since these kinds of discussions do not ensure the active participation of all students and has some other limitations. For several reasons, some students feel uncomfortable to take part in face-to-face discussions. In that case, in a web community, having the facility of participating in online written discussions could help the laggards.

\section{Difficulties in Classroom Lecture}

It is often difficult for a teacher to reach all the students and discuss with their problems in a limited hour class. For the students, it is often difficult to understand all the things and also to asking questions. For a big-sized class, individual counseling is not always a good solution and sometimes not practical. It is also a fact that by nature, some students are shy and do not respond or voice opinion in the class. Of course, applying some teaching methods like group discussion, playing learning games etc. make the class interactive but again, these do not ensure $100 \%$ participation or same level of participation due to time and other limitations. Therefore, under this circumstance, it is hard for the teacher to monitor how much his/her student understands before appearing to exams.

Furthermore, there is not much of chance for students to write in the classroom except exams. Therefore, a lot of mistakes happen in writing English sentences. Yousuf Islam conducted an investigation on the matter and the result that he found is enclosed here: "To understand the trouble students have with sentence making, 18 students in first year, first semester were given a task in free-writing - any incident in their lives that affected them. The 334 collective sentences were analyzed for the type of mistakes made. $63.5 \%$ of the sentences were found to have one or more problems. The highest type of error was subject-verb matching which was found in $19.3 \%$ of the sentences followed by preposition errors at $14.2 \%$, etc. Students who wrote correct sentences were generally found to be writing simple sentences like those of a $3^{\text {rd }}$ or $4^{\text {th }}$ grader. This whole exercise was abandoned when it was accidentally discovered that when a student was asked to repeat the whole exercise, the types of mistakes were different. After a few trials, it was concluded that errors are randomly made - students have little or no idea of sentence construction [3]".

Due to these difficulties there exist holes in knowledge that needed to be filled up by adopting alternative ways and technology might help here. 


\section{Literature Review}

Today web based learning environment has become a vital part of education. According to Jalal and Zaidieh, in the field of E-Learning, the social network sites handled the big problem raised by educators in the recent period. For example, a lack of humanitarian aspect and described it as teaching lacks spirit. However, Social networks have helped to resolve some of these problems, by adding interactive side with a human, and make the participation of the human element in the educational process something important [4]. This social network provides a wide range of tools and applications that allow users to communicate and share information (add photos, videos, comments and links, send messages, allowing integration with other websites, mobile devices, applications, e-mail, RSS feeds and other technologies) as well as control who can access specific information or perform certain actions [5].

Dorum, Bartle, Pennington has mentioned from their analysis that many educational researchers are in agreement that the sense of belonging, or the cohesion a student has with a particular institution, is one of the most important requirements to ensure individuals' proper functioning within a learning environment (Deci \& Ryan, 1985; Connell \& Wellborn, 1991; Goodenow, 1993; Finn, 1989; Osterman, 2000). Social integration is consistently found to impact student persistence, and developing valued relationships is an important part of that integration (Astin 1984; Tinto 1998). Studies show that attrition often occurs among first year students who have not been integrated into the campus community (Christie \& Dinham 1991) [6]. The sense of belonging to the student web community is deemed important: "For many youngsters starting their studies at university might be somewhat difficult, because older peers often start their studies somewhere else or stay in their home town. Especially if the high school and the university are in different towns it is inevitable that old friendships get weaker and new friendships are formed with other university students. Sometimes it is hard to get to know new friends out of the blue. It usually takes days, often weeks. Studying generally feels better, when one does not have to study alone... In the web it is easy and comfortable to meet new people and discuss with them. Starting a discussion and joining one is often easier in the web than face to face. In a social networking site in the context of university studies one can seek and find new and old studentsfrom a specific study program and get to know them already before actual start of studies as well as during the studies. This could be a convenient ice breaker for many students. Discussion face to face could be easier at the first meeting, when both could recognize one another [7]."

Madge, Meek, Wellens and Hooley (2009) conducted an investigation into the role of online social networking sites (specifically Facebook) in first year students settling in to academic and social life. In a survey of 221 students they found that more than half (55 per cent) had joined Facebook to make new friends prior to entering university, while a further 43 percent joined immediately after starting university. Nearly three quarters of the respondents said Facebook had played an important part in helping them to settle in at university. Specifically, students preferred using Facebook for social reasons, rather than for formal teaching and administrative purposes. It was concluded that Facebook functions as a "social glue" that helps students settle into university life, that keeps the student together as a community, and aids in communication (especially about social events) within the student body. However, it was also stressed that Facebook is only one aspect of student's social networking practices and clearly face-to-face relationships and interactions remain significant $[7,8]$.

Sarah Spinler, a teacher wrote her students after they got back the results on her exam and asked those who did well on specific questions to volunteer to write down very specific strategies and tips they used for studying. This type of help can be posted on course blog for all students to have access and the teacher might have to spend some class time going over some of the strategies, tips and examples and a way of helping students to learn how to learn the material [9].

\section{Methodology}

Course Blog and Wiki spaces allow students to hold online written discussions. Both of these promote editing. Blog allows the writer to post commentary and visitors to leave responses whereas wiki permits the live editing and revision of content of posted document [9]. In recent years, the evolution of the Internet led us to Web 2.0 and the emergence of online tools and applications, increasingly interactive and collaborative, examples of which are social networks [10]. Web 2.0 tools provide the ability to combine technology with collaboration. Today's students have more access to information than ever before with the help of Web 2.0 tools. But teachers must remember that simply accessing information is not enough. Students need to be able to analyze, synthesis, and evaluate information [11].

One of the e-services available in the concerned university is called 'Learning Feedback System' or LFS. Here teachers and students interact in course blogs. Students can also receive advice and corrections from their peers. Some teachers have started using the LFS in innovative ways. Students get always in touch with their teachers through LFS. For providing any urgent notice or learning materials, teachers use it. A snapshot is given in Fig 1. 


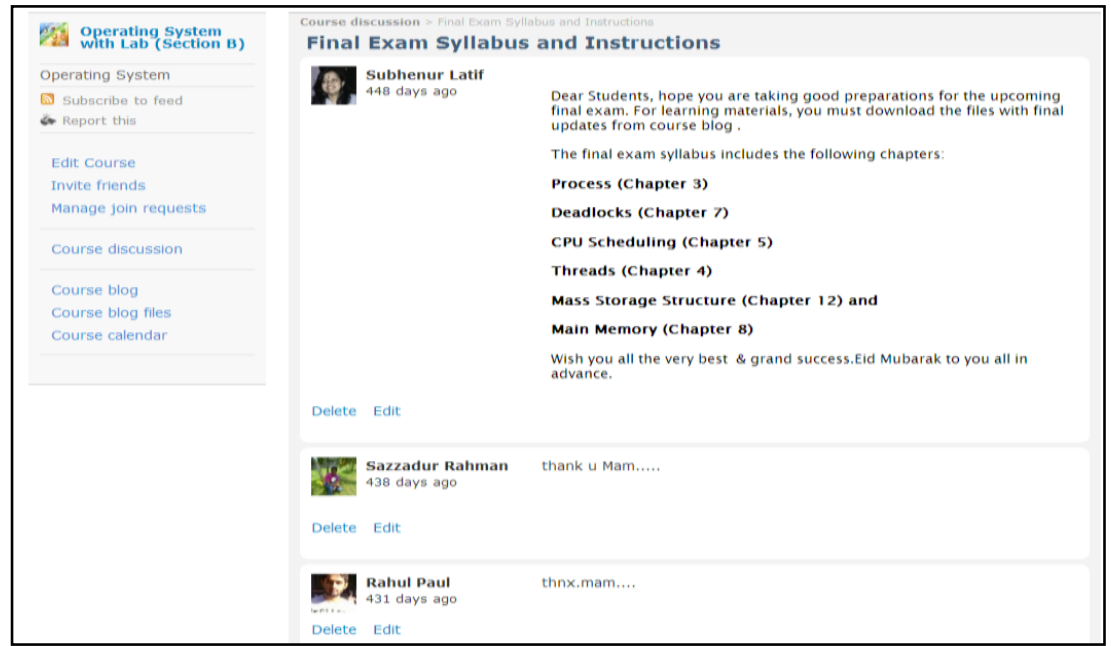

Figure 1: Snap of Teacher-student using Learning Feedback System (LFS)

Five cases had been analyzed to figure out the effects of LFS from teacher's point of view. A survey was conducted on using LFS in learning at the end of a semester. The participants were given a brief verbal explanation before starting. They were informed of their right to withdraw, asked to read the instructions carefully and to complete the questionnaire at their own pace. The findings described here are taken mostly from case studies, structured and unstructured interviews and from the experiences of instructors.

\section{Case 1:}

\section{Five Cases}

Discrete Math is a core course of CSE program and the first author is involved with designing this course for one year. The main objective of learning this course is to develop the logical reasoning ability and to train students thinking quantitatively and analyze problems critically. In class, after explaining the topic of logic and propositional logic, some of the students were found confused. Then teacher told her students to discuss on the topic in LFS. They have to discuss using their own language and examples. The discussion went on and on with more and more examples. Finally, the confused students got the point from predecessors and they gave their own examples shows in Fig 2.

\begin{tabular}{|c|c|}
\hline $\begin{array}{l}\text { Abubakar Siddique } \\
35 \text { days ago }\end{array}$ & $\begin{array}{l}\text { Logic: } \\
\text { Logic specify the meaning of mathematical statements. These } \\
\text { help us understand and reason with statements. Logic is the } \\
\text { basis of all mathematical reasoning, and of all automated } \\
\text { reasoning. It has practical applications to the design of computing } \\
\text { machines, to the specification of systems, to artificial intelligence, } \\
\text { to computer programming, to programming languages, and to } \\
\text { other areas of computer science, as well as to many other fields of } \\
\text { study. } \\
\text { Proposition: } \\
\text { A proposition is a statement which has truth value: it is } \\
\text { either true (T) or false (F). } \\
\text { Example: Which of the following are propositions? } \\
\text { (a) } 17+25=42 \\
\rightarrow \text { (a) is a proposition; it has the 'truth value' or it's true. } \\
\text { (b) Is the moon round? } \\
\rightarrow \text { (d) is not a proposition. It's a question. } \\
\text { (c) } 7 \text { is greater than } 12 \text {. } \\
\rightarrow \text { (c) is a proposition. It's false. } \\
\text { (d) } x \text { is greater than } y \text {. } \\
\rightarrow \text { (d) is not proposition, because until we know the } \\
\text { values of } x \text { and } y \text {, we can't actually say whether it } \\
\text { is true or false. }\end{array}$ \\
\hline
\end{tabular}

Case 2:

Fig 2: Student is giving examples from his own idea

An assignment topic was "Benchmarking of OS: Linux, Windows and Apple Mac". A vacation was going on then and the students had no option to meet the teacher but they had to submit the assignment. Nobody understood what they have to do exactly. At first, students and the teacher had discussed in LFS on the term, "Benchmarking" because this word was not familiar to them. After understanding the topic fully, they started to submit the assignment which is shown in Fig 3 and Fig 4. 


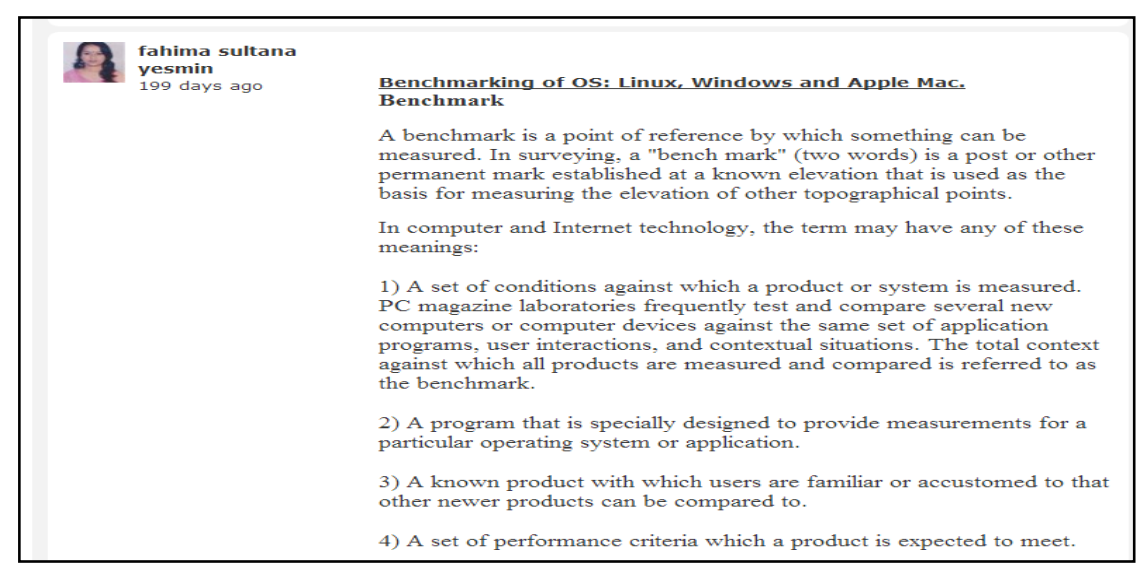

Fig 3: Student is explaining the idea behind the assignment topic

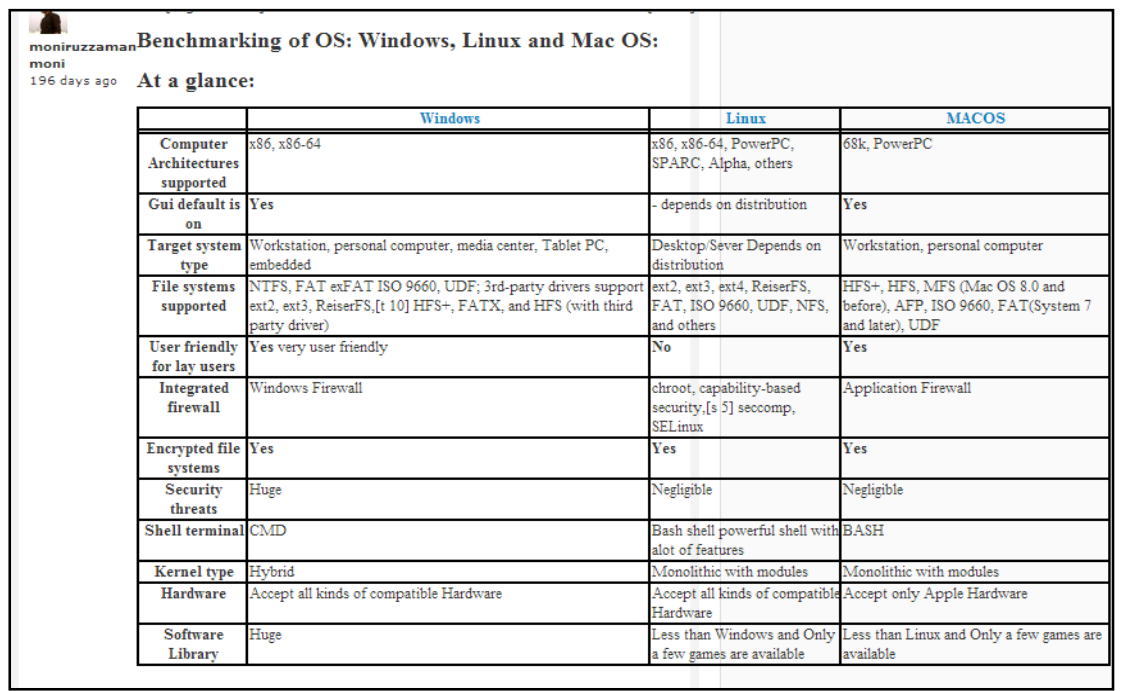

Fig 4: Student submitted the assignment

Case 3:

Students were so anxious about their exams especially for the big ones that carry good proportion of marks like mid-term and final-term. To reduce the fear, teacher had designed a sample question for his students and shared it in LFS before exam [Fig 5]. The result was very positive.

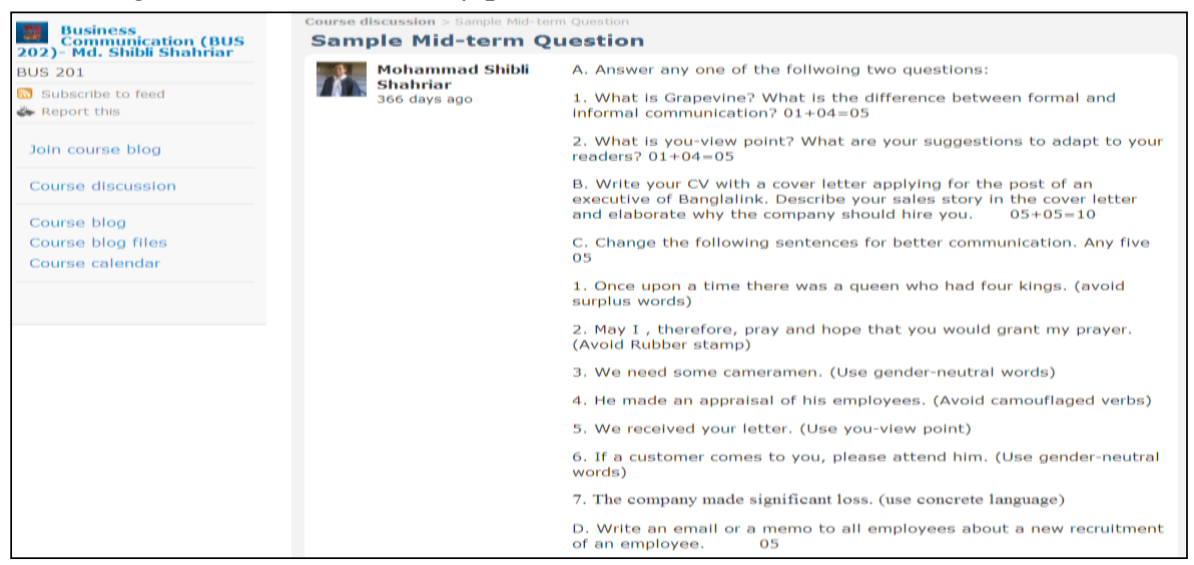

Case 4:

Fig 5: Teacher's post on model question

The students of a course performed very poorly in their mid-term exam. In LFS, the teacher of that course uploaded the whole question of exam and required each student to make TWO posts in the course blog. The first problem was that students personally faced to answer that question during exam. In their second post, they were asked to explain any of the two problems faced by others that they themselves understood well. Both posts carried marks. One student of that course wrote about 37 words in response to the first post (Fig. 6). But in 
his second post, the total number of words he wrote was above 100 (Fig 7). Similar thing happened for others that are the average word responses was more than double in case of post-2. It shows that one has to write more as well as think more when he/she is required to explain something to others (Peer Teaching) [1].

TWO PROBLEM
1. I don't understand how I can comand from the program above and how the computer would
carry out the comand.
2. I don't understand, when we give wrong statement into the computer then how would the
program run.
Nazmul Hasan Nahid 193 days ago

Fig. 6: Post comprising comments on own problems

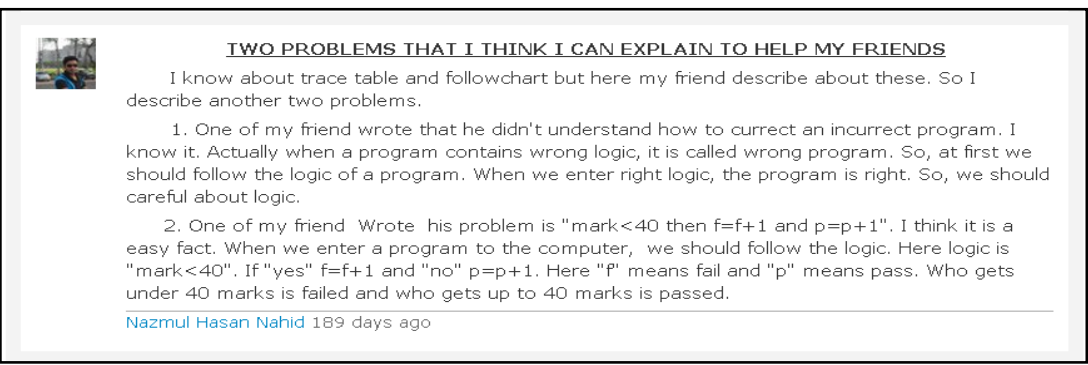

Fig. 7: Post comprising explanations on other's problems

Case 5:

A business department teacher asked his students to collectively write the job description of a job not given in the text. The first student to enter the blog could only write a sentence. The second student looked at this and added two more sentences. By the time 10 students entered, almost a page of description was ready. The $11^{\text {th }}$ student reformatted the entire job description to make better sense. This way the whole class developed a sense that they could do things collectively and that they should be now able to attempt job descriptions on their own! $[1,2]$.

\section{Feedback from Students}

At the end of the semester, a survey was conducted to take the feedback from the students of a particular section (about 45 students) on their experience of using LFS (Figure 8). Some comments of the students have been mentioned here:

- LFS provides us a space to interact.

- I think it develops our writing skill.

- When I see other answer then I could think deeply and it helped me a lot.

- LFS benefited me to check my answer with others. By the help of LFS we prepare our own answer easily.

- I have personally benefitted from the sample mid-term question.

- LFS helps us to communicate with others. It is a chain of our circle.

- It helps me to explain my own words to everyone.

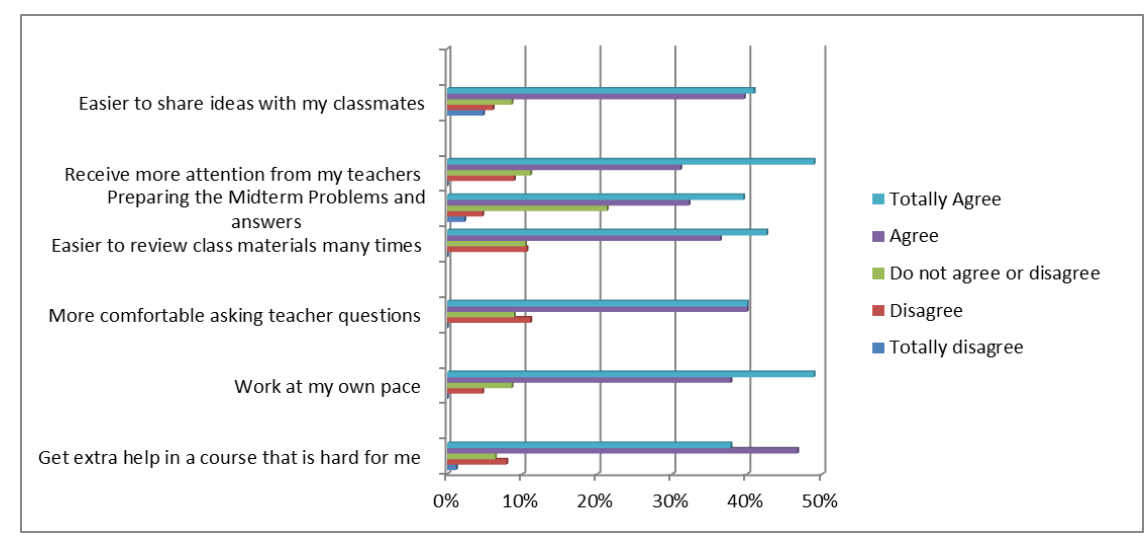

Figure 8: Chart depicted student feedback on LFS 
Figure 8 shows the survey result which is a demonstration of positive impacts of LFS on students. Students were mostly agreed upon the issues that were related with their convenience in interactive learning.

\section{Discussion}

Outside the classroom, student feels the sense of belonging in learning when they got an online academic network or web community monitored by their teacher. To fill up the gaps in terms of learning, they can use open discussion facility anytime that is seen from Case 1 and Case 2.

Despite of getting all supports from the teacher, students always get frightened of exams. Sometimes from this fear they get nervous that hamper their performance. In Case 3, the teacher had applied a technique through LFS where he shared the sample pattern of questions. That got very good appreciation from students. The numbers of word responses in Case 4 indicate that it involves students to write and enhance the willingness to write even for them who lack basic communication skills in English. The comparison of average word responses written in post-1 (37.75) and post-2 (170.75) shows that it engage students more in writings when they are about to teach something to other peer. Hence, a platform like this gets students more involved in the writing process, thus strengthening writing, editing and communication skills where using technology in higher education had also been practiced. Such practice is advantageous for both students and teachers. Written discussion helps shy people or those who are having trouble with English to add their ideas, in their own pace [9]. They get used to write authentic language.

Collaboration is a 21 st Century skill of increasing importance and one that is used throughout the learning process. It is not an integral part of the learning process for the individual, One does not have to collaborate to learn, but often one's learning is enhanced by doing so [12]. Case 5 represents the example of such collaborative and collective learning.

Learning Feedback System has been initiated for the betterment of teaching and learning. As it is a web-based system, it would be applicable for any course; for any size of class accessible from anywhere; anytime. Once students start interactively using this system, they can view and share each other's thoughts and problems. The benefits of using this feedback system are as follows [13]:

- Finding out what students have learned in class

- Sharing problems if they don't understand any topics or lessons

- $\quad$ Supporting each other

- Collective solutions

- Collective learning

- Ownership of learning

Researchers always make a comment that students learn only $5 \%$ to $10 \%$ from the lectures deliver in the classroom and from reading [13]. If students continue to write like this in all their four years at the university, by the time they graduate, they hopefully would be much more fluent in their courses and their English writing ability. Students can be inspired to communicate with teachers on using this learning feedback system and some bonus marks might be given for that.

\section{Limitations and Suggestions}

Requirements of Internet and Computer, problem of plagiarism, defining grade point etc. are some limitations of using LFS. According to Shibli Shahriar, the following are the hindrances in engaging students in LFS [13]:

1. Fear of mistakes: Students might be afraid of mistakes when they want to join in the discussion with other fellow students.

2. Access to Internet: Some students don't have any access to internet or they may think that using internet will be costly for them compared to its benefits derived from writing.

3. Lack of creativity: Many students didn't learn to think as they feel teachers will give those questions and they will memorize them

To enhance the participation and to reduce the dropout rate, the followings are suggested [1]:

- A tutorial class on practically using LFS

- Sufficient computers and internet facility

- Intrinsic and extrinsic motivation to participate in discussion

- Designing questions that make sure to stop copy and paste culture

- A handsome grade point for participation in blog posts

\section{Conclusion}

Technology has given a new dimension in teaching and learning. In the current age of science and technology, it's the duty of teachers to prepare their students to face the real world. To do that, effective ways 
are needed to be brought into light [1]. The Internet has gradually leaved its originals tools for writing and reading, and entering a more social and participatory [15]. Tim O'Reilly \& Battelle (2009) has favored Web 2.0 as a better and quicker adaptation of students to technology, to the extent that Internet has become a platform simple and easy to use that corresponds to their interests and personal needs benefiting the collective intelligence [16]. The Learning Feedback System can be used as a great tool to engage students in a collaborative environment where they are always in touch with teacher and thus strengthening the sense of belonging. Teachers can motivate their students to participate more and more in online written discussions as the result of this research shows it actually help students to get rid of confusions and getting confidence in an interactive learning process.

\section{References}

[1] Subhenur Latif and M Lutfar Rahman."Improving Skills by Peer Learning through Web Technology".National Conference on Teaching Learning at Tertiary Level in Bangladesh, December, 2011.

[2] Ben McNeely.Using Technology as a Learning Tool, Not Just the Cool New Thing, Educating the Net Generation, February 2005.

[3] Yousuf Islam. "Tertiary Education in Bangladesh - Brief History, Problems and Prospects", International Journal for the Scholarship of Teaching and Learning, Vol. 5, No. 2, pp-4, July 2011.

[4] Jalal and Zaidieh. "The Use of Social Networking in Education: Challenges and Opportunities". World of Computer Science and Information Technology Journal (WCSIT).Vol. 2, No. 1, 18-21, 2012.

[5] Brandtzaeg, PetterBae \& Heim, Jan; (2007). Initial context, user and social requirements for the Citizen Media applications: Participation and motivations in off- and online communities.Citizen Media Project.

[6] Dorum, Bartle, Pennington. "The Effect of Online Social Networking on Facilitating Sense of Belonging among University Students Living Off Campus". World Conference on Educational Multimedia, Hypermedia and Telecommunications (EDMEDIA) 2010. Toronto, Canada. June 29, 2010.

[7] Silius, Miilumäki, Huhtamäki, Tebest, Meriläinen, Pohjolainen. Social Media Enhanced Studying and Learning in Higher Education. IEEE EDUCON Education Engineering, Madrid, Spain, April 14-16, 2010.

[8] Madge, C., Meek,J., Wellens, J. \& Hooley, T. (2009). Facebook, social integration and informal learning at university: 'It is more for socialising and talking to friends about work than for actually doing work'. Learning, Media and Technology, 34(2), $141-155$.

[9] 2013.University of the Sciences Website. [Online]. Available: http://www.usciences.edu/teaching/tips/spal.shtml

[10] Patrício and Gonçalves. "Facebook In The Learning Process: A Case Study". Proceedings of ICERI, 2010 Conference.15th-17th November 2010, Madrid, Spain.

[11] The web2technologies Website.[Online]. Available: http://www.web2teachingtools.com/developing-critical-thinking-skills.html

[12] Andrew Churche (2011). The Educational Origami blog and wiki. Available: http://edorigami.wikispaces.com/Bloom's+Digital+Taxonomy\#toc12

[13] Shibli $\quad$ Shahriar $\quad$ (2011).Daffodil International Available:http://forum.daffodilvarsity.edu.bd/index.php?topic=4622.msg21529\#msg21529

[14] National Training Laboratories. Bethel, Maine. Available: http://stephenslighthouse.com/2010/02/26/the-learning-pyramid/

[15] MAZMAN, SacideGuzin\& USLUEL, YaseminKoçak; (2009). The Usage of Social Networks in Educational Context. Available: http://www.waset.org/journals/waset/v49/v49-76.pdf

[16] O'REILly, Tim \& BATTELLE, John; (2009). Web Squared: Web 2.0 Five Years On. Available: http://www.web2summit.com/web2009/public/schedule/detail/10194 